\title{
Desenvolvimento de traços estruturais curvilíneos em cinturões de empurrões: visualização em modelagem física
}

\author{
Fernando César Alves da Silva ${ }^{1}$ \& Fabiano Jackson da Silva Oliveira ${ }^{2}$
}

\begin{abstract}
Resumo O modelamento físico de estruturas compressionais, utilizando-se aparato tipo caixa de areia realizados no Laboratório de Modelamento Estrutural do PPGG (UFRN), possibilitou o estudo dos aspectos geométricos dos traços estruturais desenvolvidos em orógenos compressionais. Os experimentos mostraram que esses traços geralmente possuem geometria curvas gerando saliências e reentranças. A presença de obstáculos nas regiões de ante-país e pós-país, deslocados lateralmente, produz além de empurrões/retro-impurrões, estruturas com fortes componentes oblíquos, tendendo a transcorrentes. Essas estruturas transcorrentes servem de ponte de ligação entre diferentes segmentos da frente de deformação, mas ocorrem também, em menor escala, como par conjugado em frente ao endentador. Os mergulhos dos planos dos empurrões e retro-empurrões mostram um pequeno decréscimo com o aumento da deformação. Os rejeitos exibidos por essas falhas exibem um forte incremento a partir de 15\% de encurtamento. A comparação das estruturas geradas em laboratório com aquelas encontradas em orógenos naturais de diferentes idades revelou a presença de aspectos comuns, sugerindo que esse tipo de experimento pode contribuir para a compreensão do desenvolvimento de estruturas naturais.
\end{abstract}

Palavras-chave: caixa de areia, empurrão, saliências, reentrância.

\begin{abstract}
Development of curve structural trends in thrust belts: insights from physical modeling. Sandbox apparatus was used to investigate the development of the curved structural trends usually mapped in compressional orogens. The experiments were setup with two additional blocks as obstacles located in the hinterland and foreland portions. The structures generated due to shortening exhibited curve geometry like salients and recesses. Forward and backward thrusts faults developed simultaneously. The two segments of the main thrust lead edge were separated by transcurrent faults. Minor conjugated transcurrent faults also occur near the corner of the hinterland identator (moving block). With progressive shortening the dip of faults (thrusts and backthrusts) were slightly rotated while the throw increased greatly after $15 \%$ of shortening. The common features exhibited by both experimental models and natural orogens suggest that physical experiments may shed light in the comprehension about the generation of natural structures.
\end{abstract}

Keywords: sandbox, thrusts, salience, reentrance.

INTRODUÇÃO Cinturões de cavalgamento geralmente exibem, em mapa, traços curvos, a exemplo dos orógenos Himalaia e Sangihe-Halmahera na Ásia (Taponier et al. 1982, Moores \& Twiss 1995, respectivamente); Alpes (Ravaglia et al. 2006), Apalaches (Spranggins \& Dunne 2002), Salvador-Curaçá no Brasil (Barbosa \& Sabate 2000), Alice Springs e Petermann na Austrália (Flottmann et al. 2004), entre outros (Fig. 1). Nesses cinturões, os segmentos curvos correspondem a saliências, reentrâncias, oroclinais, sintaxes e arcos. Saliências (curvaturas antitaxiais) e promotórios são segmentos curvos cuja convexidade dispõe-se na direção do transporte tectônico. O termo saliência é empregado em região de ante-país de cinturões de dobras e empurrões, onde a protuberância dispõe-se na direção do interior continental (Fig. 2a) enquanto promotório refere-se à protrusão de uma margem continental em direção ao oceano (Fig. 2b). Quando a concavidade (em vez da convexidade) é na direção do transporte tectônico, essas estruturas são denominadas reentrâncias ou recessos (eventualmente os termos sintaxes ou curva sintaxial também são empregados). O termo reentrância é usado para expressar uma indentação ou grande baia ao longo de uma margem continental (Fig. 2b) (Marshak, 2004). O termo oroclinal, embora usado na literatura de forma mais ampla, originalmente refere-se a estruturas cuja forma curva foi adquirida por progressivo encurvamento de traços estruturais inicialmente retos em torno de um eixo vertical (Marshak, 1988).

As curvaturas descritas, exibidas em mapas de cinturões orogênicos, têm atraído à atenção da comunidade geológica há várias décadas, uma vez que o entendimento da sua gênese contribui para o entendimento dos processos orogenéticos (Marshak, \& Flottmann 1996,

1 - UFRN, Centro de Ciências Exatas, Departamento de Geologia, Bolsista de Produtividade em Pesquisa do CNPq, Natal (RN), Brasil.

E-mail: fernando@geologia.ufrn.br

2 - UFRN, Departamento de Geologia, Programa de Iniciação Cientifica, Curso de Geologia, Natal (RN), Brasil.

E-mail: fabianojackson@yahoo.com.br 

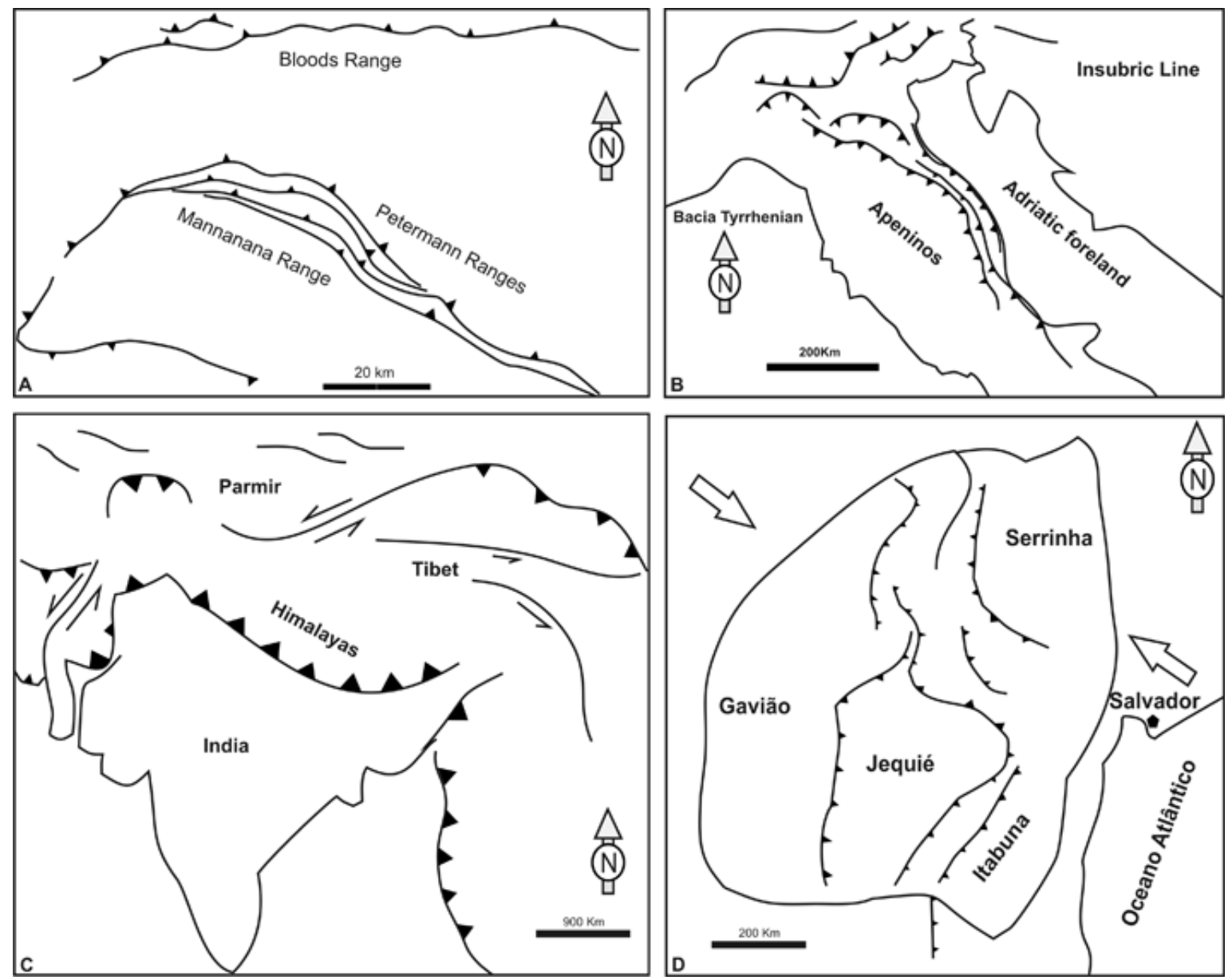

Figura 1 - Exemplos de cinturões com traços estruturais curvos. A) Petermann Ranger (modificado de Flottmann et al. 2004). B) Apennines (Ravaglia et al., 2006.), C) Himalaias (modificado de Moores \& Twiss 1995). D) Cinturão Salvador-Curaçá, Cráton do São Francisco, BA (modificado de Barbosa \& Sabaté 2000).

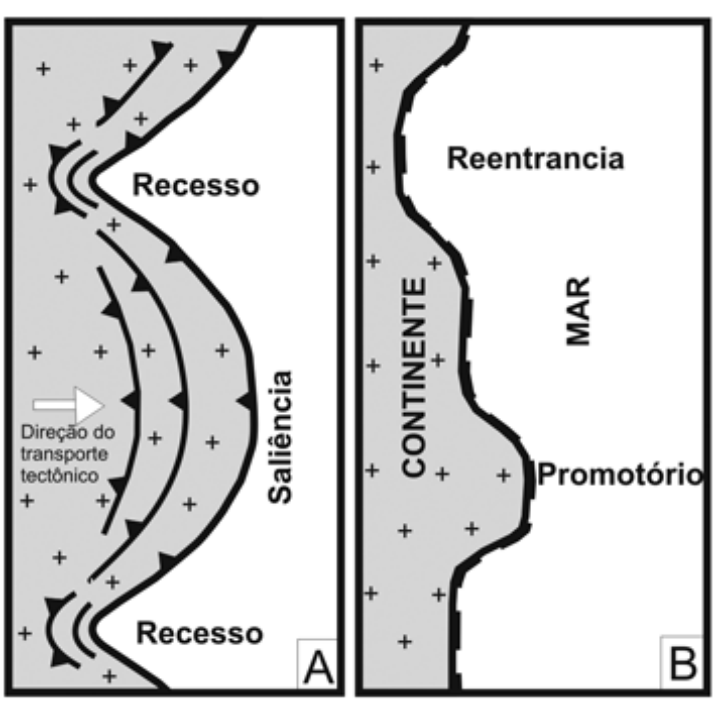

Figura 2 - Exemplo da terminologia empregada para traços curvos (em mapa) desenvolvidos em regiões orogênicas. A) Diferença entre saliências e recessos com base na disposição da concavidadelconvexidade, em relação à direção do transporte tectônico. B) Relação entre promotório $e$ reentrância. (Modificado de Marshak 2004).
Spranggins \& Dunne 2002, Marshak 2004). Adicionalmente, o interesse econômico tem contribuído para um melhor conhecimento das curvaturas, na medida em que constituem sítios favoráveis à acumulação de óleo e gás, como na bacia de Amadeus (maior produtor em terra da Austrália, Flottmann et al. 2004) (Fig. 3) ou na porção sul dos Apennines (Turrini \& Rennison 2004).

$\mathrm{Na}$ simulação física apresentada mais adiante neste trabalho, ênfase será dada a formação e desenvolvimento das saliências. Dependendo da geometria que seus elementos constitutivos exibem em planta, as saliências podem ser classificadas em vários tipos (Macedo \& Marshak 1999). Quanto à morfologia da falha mais distal do sistema ou frente de cavalgamentos (leading-edge), elas podem ser: simétricas parabólicas, assimétricas parabólicas, de cresta plana ou irregulares (Fig. 4a). Quanto à geometria dos traços internos (Fig. 4b), são classificas como paralelas (i.e., Tennessee), convergentes, em uma ou nas duas terminações (i.e. Verkhoyansk), divergentes (i.e., Nackara), truncadas em uma extremidade (i.e., Mackensie) ou internamente caóticas (Macedo \& Marshak 1999).

A maioria das curvas descritas pelos traços estruturais dos cinturões orogênicos reflete a arquitetura 


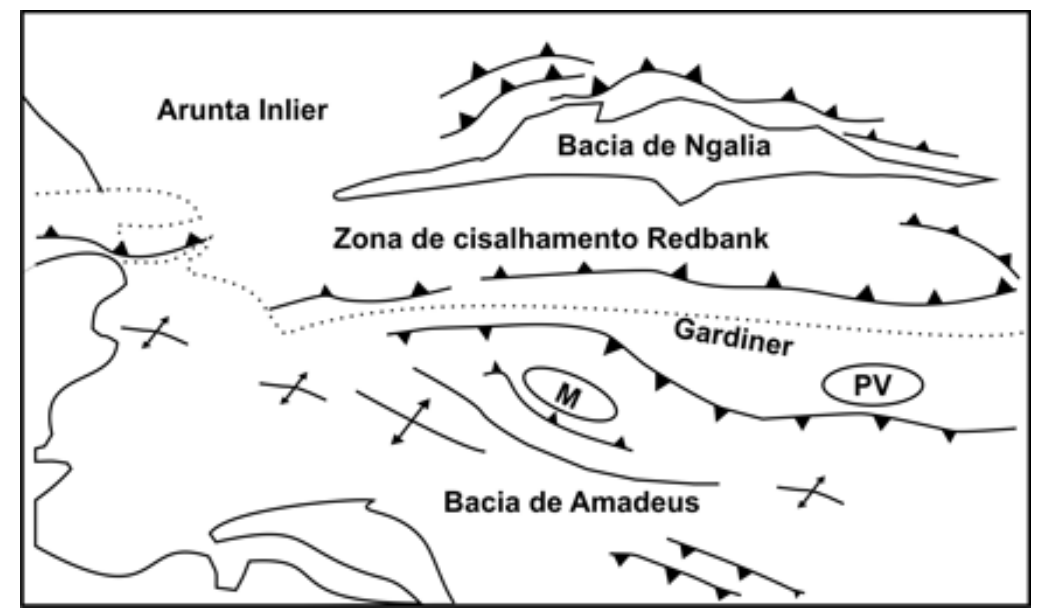

Figura 3 - Curvaturas dos traços estruturais e a localização de campos de óleo e gás na bacia de Amadeus região central da Austrália. M: Campo de óleo e gás de Mereenie; PV: Campo de gás Palm Vallay. (Modificado de Flottmann et al. 2004).

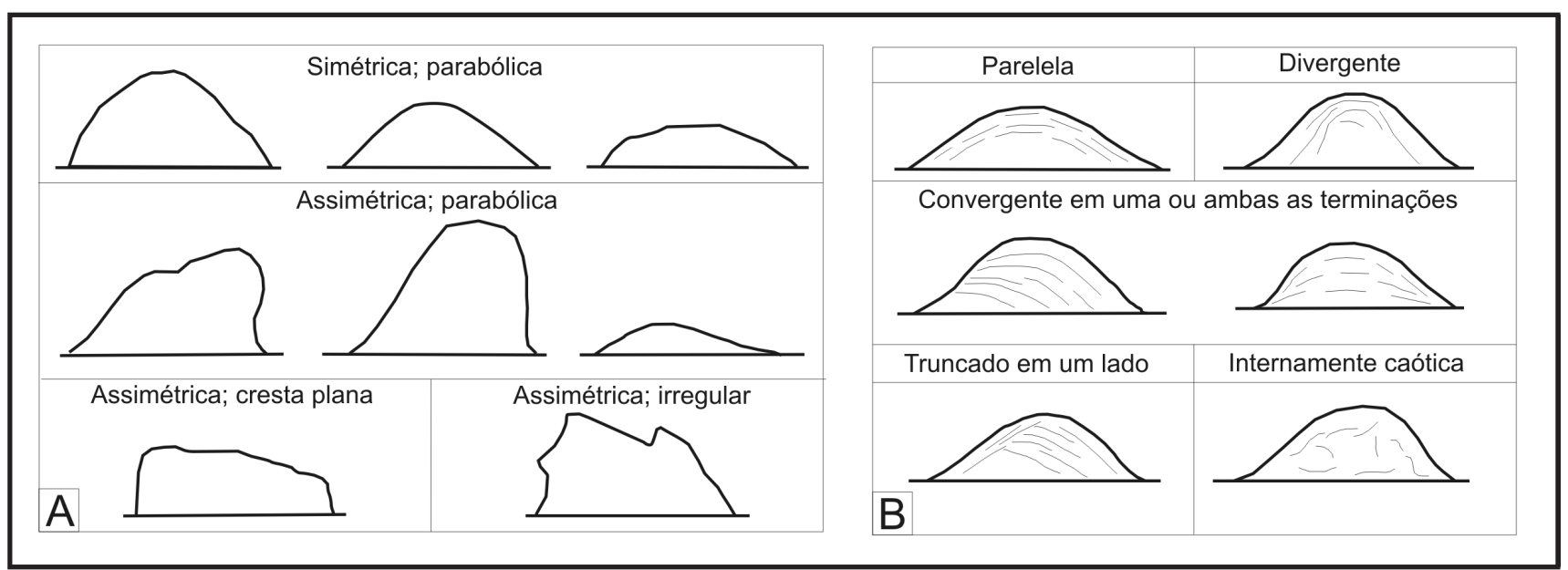

Figura 4 - Classificação das saliências de acordo com sua morfologia externa (A) e interna (B). Modificado de Marshak 2004.

e propriedades mecânicas do preenchimento da bacia sedimentar antes da deformação. Porém, algumas delas têm outras causas para o seu desenvolvimento. Entre as causas de origem bacinal estão as variações na espessura do preenchimento da bacia, a inclinação do descolamento basal, a ação de plutonismo, além da forma da bacia e irregularidades de segmentos litosféricos convergentes (Marshak \& Flottmann 1996). A interação de um cinturão de cavalgamentos com obstáculos ou promotórios na região de ante-país ou colisão de um endentante na região de pós-país também podem levar a formação das curvaturas (Paulsen \& Marshak 1999, Marshak 2004).

A fim de complementar os estudos de campo, experimentos analógicos de desenvolvimento de cinturões de empurrões e dobramentos foram realizados por vários autores (entre vários outros podemos citar Turrini \& Rennison, 2004, Yamada \& MacClay, 2004, Del Ventisette et al., 2006, Konstantinovskaya et al., 2007, esses dois últimos lidam com a inversão de bacias e a reativação de falhas). $\mathrm{O}$ trabalho ora apresentado inse- re-se nesse contexto e difere dos trabalhos precedentes pela presença e disposição diametralmente oposta dos blocos que serviram de endentante, na região de póspaís e obstáculo na região de ante-país. Como objetivos citamos a visualização dos diversos estágios de formação das saliências neste tipo de ambiente, a influência da disposição dos blocos na geometria das estruturas resultante da convergência e, por fim, a comparação da configuração final obtida nos experimentos com alguns segmentos de orógenos naturais. Não se enquadra no escopo deste trabalho, simular a deformação em um orógeno em particular, e sim em determinadas estruturas e compará-las do ponto de vista geométrico, a estruturas naturalmente formadas e descritas na literatura.

MATERIAIS E MÉTODOS Com a finalidade de observar o desenvolvimento de segmentos estruturais curvos em cinturão de cavalgamentos, realizamos experimentos em aparato tipo 'caixa de areia'. O aparato teve dimensões $50 \mathrm{~cm}$ x $40 \mathrm{~cm}$ x $20 \mathrm{~cm}$ (comprimento, 
largura, altura, respectivamente) e a velocidade da parede móvel foi da ordem de $0,04 \mathrm{~cm} / \mathrm{s}$. A pilha rochosa, constituída de areia colorida artificialmente, para simular camadas e criar um referencial para visualização das falhas, tinha espessura média de $5 \mathrm{~cm}$. A areia utilizada foi oriunda das dunas eólicas da cidade de Natal, possuindo granulometria entre $100-300 \mu \mathrm{m}$. Para a montagem do modelo, a areia foi peneirada na caixa de vidro de uma altura de cerca de $15 \mathrm{~cm}$. Uma malha quadrática foi desenhada na superfície do modelo a fim de possibilitar uma melhor visualização das estruturas formadas durante a deformação. A utilização de areia seca deve-se ao fato de que, na escala de laboratório, ela simula bem o comportamento da crosta superior (Koyi et al. 2004, Eisenstadt \& Sims 2005). O experimento foi desenvolvido com uma compressão frontal (assumida como NS) e a presença de um obstáculo retangular, com bordas verticalizadas, na região de ante-país. Obstáculo semelhante foi colocado também no anteparo a fim de criar irregularidade nessa região (pós-país) e funcionar como um endentante (Fig. 5).

\section{RESULTADOS}

Geração de traços curvos em mapa $\mathrm{O}$ estágio inicial do experimento $\left(\mathrm{T}_{0}\right)$ é mostrado na figura 6 , onde se pode observar a disposição dos blocos em relação à direção de encurtamento e os perfis juntos aos blocos de pós-país e ante-país que vão monitorar o desenvolvimento de empurrões/retro-empurrões em função do posicionamento dos blocos.

$\mathrm{Na}$ macroescala (em relação ao experimento), quando o encurtamento atinge $5 \%$, um segmento da frente de cavalgamento desenvolve-se em frente ao alto do embasamento (ante-país) enquanto outro se formou ao lado dele. Uma saliência é mapeada a leste do obstáculo do ante-país e a frente do bloco móvel do pós-país, enquanto o recesso tende a se formar a frente do bloco

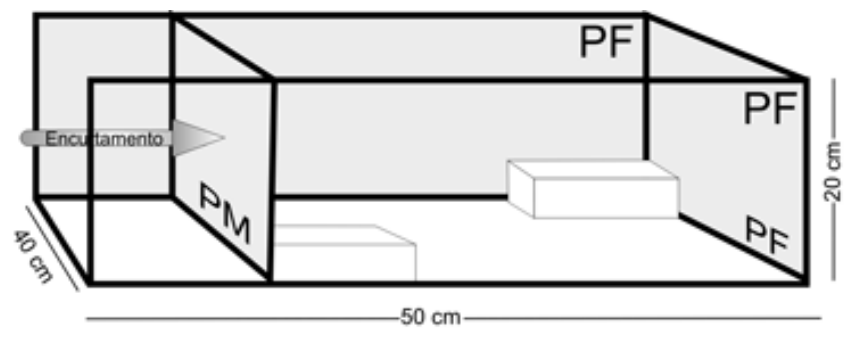

Figura 5 - Desenho esquemático do aparato usado nos experimentos (sem o preenchimento). Notar o posicionamento dos blocos nas regiões de ante-país e pós-país. PM= Parede móvel (na região de póspaís); $P F=$ Parede fixa (na região de ante-país).

do ante-país. A nucleação dessas primeiras estruturas gera uma cunha de empurrão cuja largura é da ordem de $14,5 \mathrm{~cm}$, que compreende a distância do bloco móvel ao traço da falha em superfície representada por $d$ na figura 7. A relação deste parâmetro com a espessura da pilha de areia fornece valores ligeiramente acima daqueles reportados por Marshak \& Wilkerson (1992) (Fig. 7). Nesse estágio inicial, aparentemente, os efeitos do obstáculo ou alto do embasamento situado no antepaís ainda não se fazem muito evidentes. O papel do ententante e, em parte, a fricção nas paredes, influenciam na variação no valor de $\underline{\mathbf{d}} \mathrm{e}$, portanto, do surgimento da curvatura. Para este valor de encurtamento, os empurrões com vergência para o ante-país são bem definidos enquanto os retro-empurrões são nucleados de forma diacrônica, sendo mais bem desenvolvidos junto ao bloco móvel, enquanto aquele a oeste deste bloco é quase imperceptível (Fig. 7).

No estágio $\mathrm{T}_{2}$, representado $10 \%$ de encurtamento, os dois segmentos da frente de cavalgamento foram unidos por uma ponte de direção nordeste (nucleada no

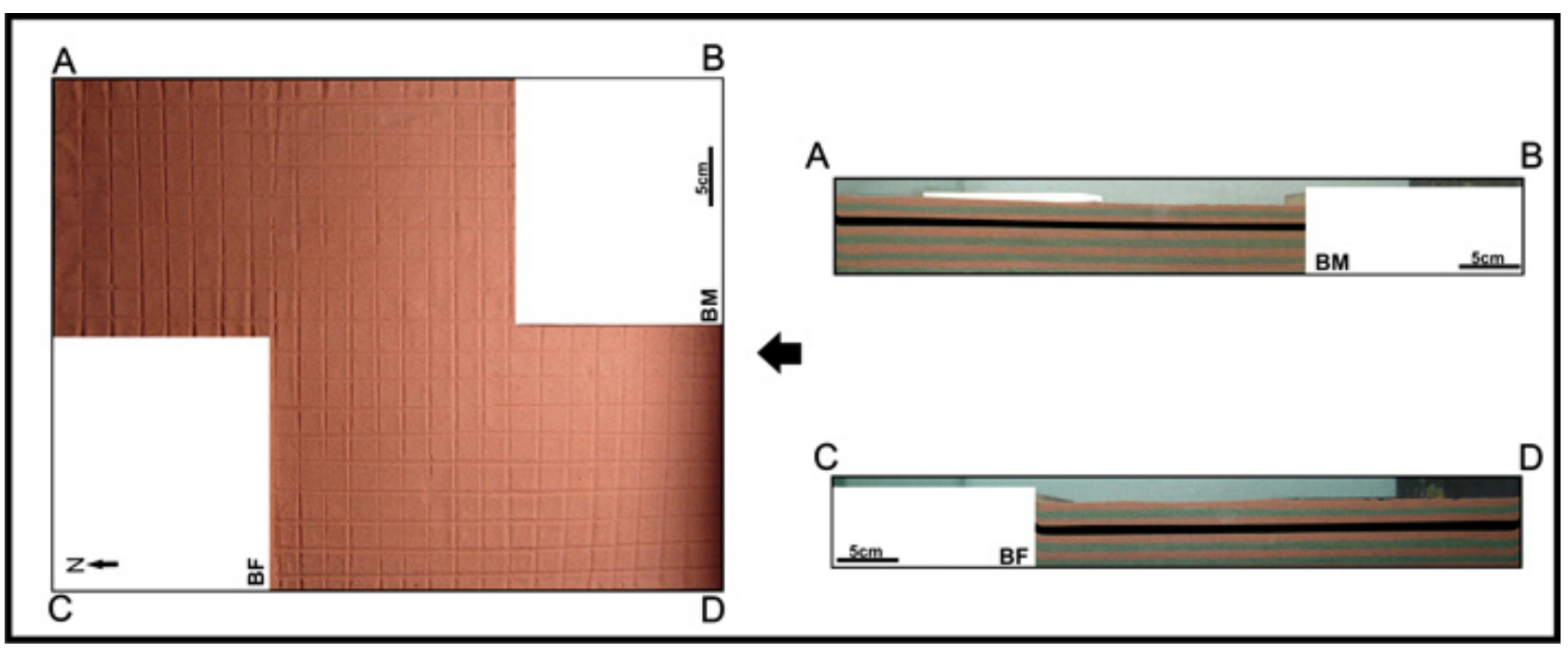

Figura 6 - Fotografias do estágio $T_{0}$ do modelo, ilustrando a disposição em mapa e perfil nas porções Este e Oeste, onde serão monitoradas as estruturas influenciadas pelos blocos no pós-país e ante-país, respectivamente. A seta mostra o sentido da compressão. 
estágio anterior) com movimentação oblíqua e importante componente transcorrente sinistral (ZT na Fig. 8). Essa geometria é influenciada pelas margens verticalizadas do bloco móvel e se desenvolve a cerca de $25^{\circ}$ com a direção de compressão. Em perfil, como o retro-empurrão junto ao bloco móvel é mais evoluído, uma estrutura do tipo pop-up é melhor visualizada nesta região (Fig. 8). Com a progressão da deformação (16\% de encurtamento) observa-se na porção leste da ZT, entre esta e a região de pós-país, uma zona de dilatação/extensão na direção paralela a frente de cavalgamento e perpendicular ao esforço compressivo (Fig. 9). Em contrapartida, na porção oeste desenvolve-se nova falha, de rejeito oblíquo, reversa, e cinemática sinistral (transpurrão).

Na parte interna da saliência, a leste do obstáculo de ante-país, é nucleado novo e pequeno segmento de empurrão cujo traço, em superfície, é curvo e a concavidade é oposta àquela da saliência mais antiga (Fig. 9). Geneticamente esta estrutura é relacionada ao transpurrão sinistral da parte oeste da ZT. A diferença na orientação dos limites do obstáculo (um EW e outro NS) e o mergulho vertical destes limites interferem na resposta do material frente a uma direção de compressão nortesul. Por conseguinte a geometria da "esquina" do obstáculo de ante-país desempenhou um papel importante na geometria e orientação deste segmento de empurrão.

Com o aumento da deformação (estágio $\mathrm{T}_{4}, 21 \%$ de encurtamento), novos empurrões aproximadamente paralelos ao anterior, mas com geometria mais irregular, se desenvolvem a frente do obstáculo na região de ante-país (oeste do modelo, Fig. 10). Na escala desse segmento, nota-se curvas sintaxiais e antitaxiais, indi-
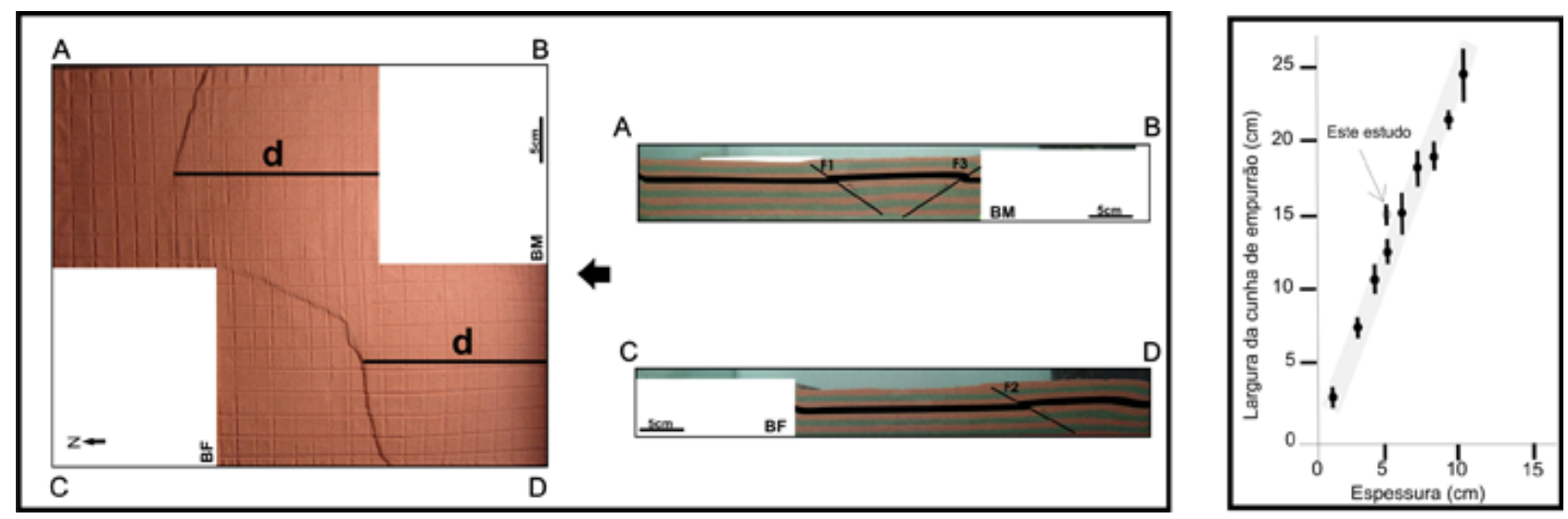

Figura 7 - Fotografias do estágio $T$ do modelo (5\% de encurtamento), ilustrando a geometria dos empurrões em planta e em perfil nas porções $E$ e $W$. Notar o maior desenvolvimento do retro-empurrão no perfil AB. $O$ gráfico mostra a relação entre a espessura e a largura da cunha de empurrão (d). O valor de d encontrado fica um pouco acima dos valores médios reportados na literatura.

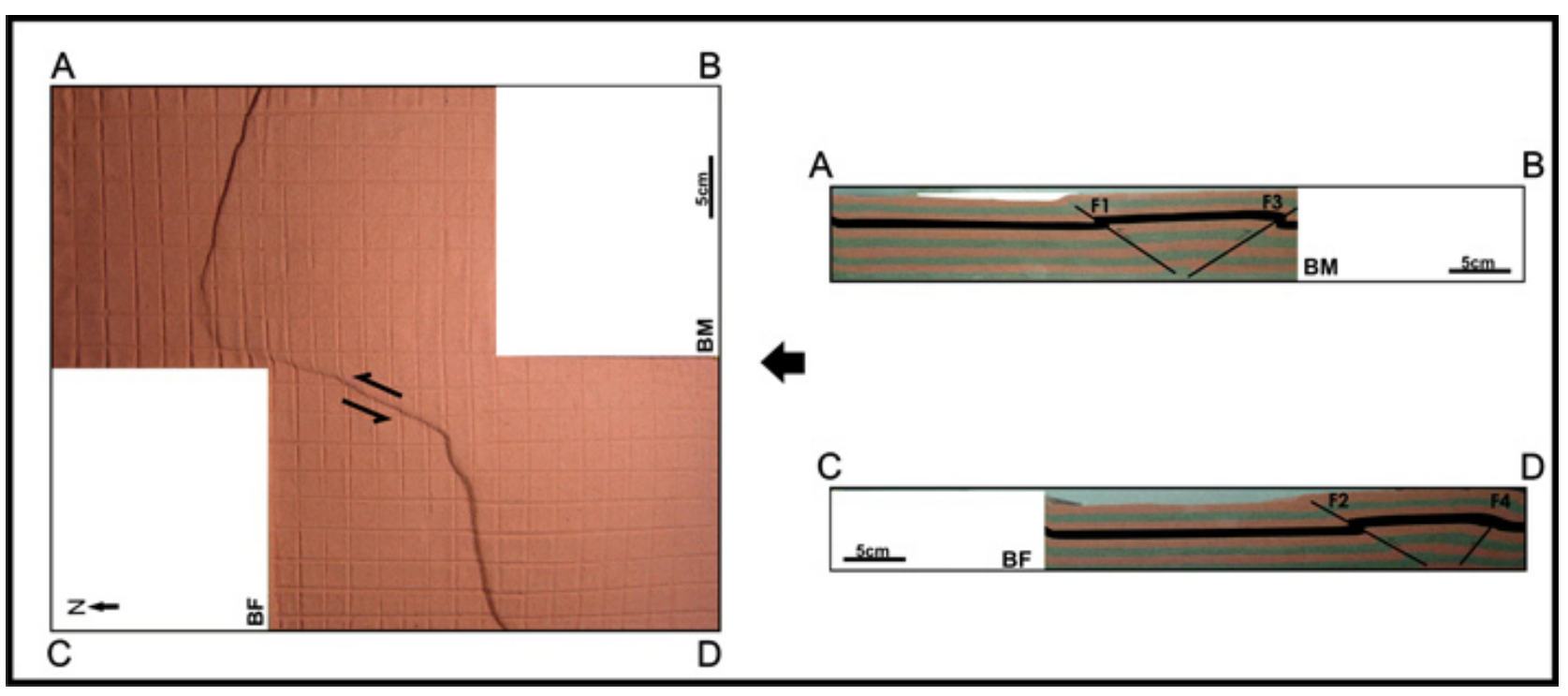

Figura 8 - Em 10\% de encurtamento, uma ponte transcorrente sinistral faz a ligação entre os segmentos da frente de cavalgamento. Na porção leste (perfil $A B$ ) o empurrão e o retro-empurrão definem uma estrutura tipo pop-up bem marcada. 
cando que a presença de obstáculo (de dimensões compatíveis com as curvas) para sua formação pode não ser uma premissa universal. No lado leste do obstáculo o novo empurrão tem uma disposição mais linear e oblíqua em relação ao precedente. A análise dos perfis reve- la, em consonância com o observado em mapa, que os empurrões são mais desenvolvidos na região a frente do obstáculo de ante-país, em relação à do pós-país (Fig. 10). Nesse último, a deformação foi acomodada por um maior desenvolvimento de retro-empurrões, levando a

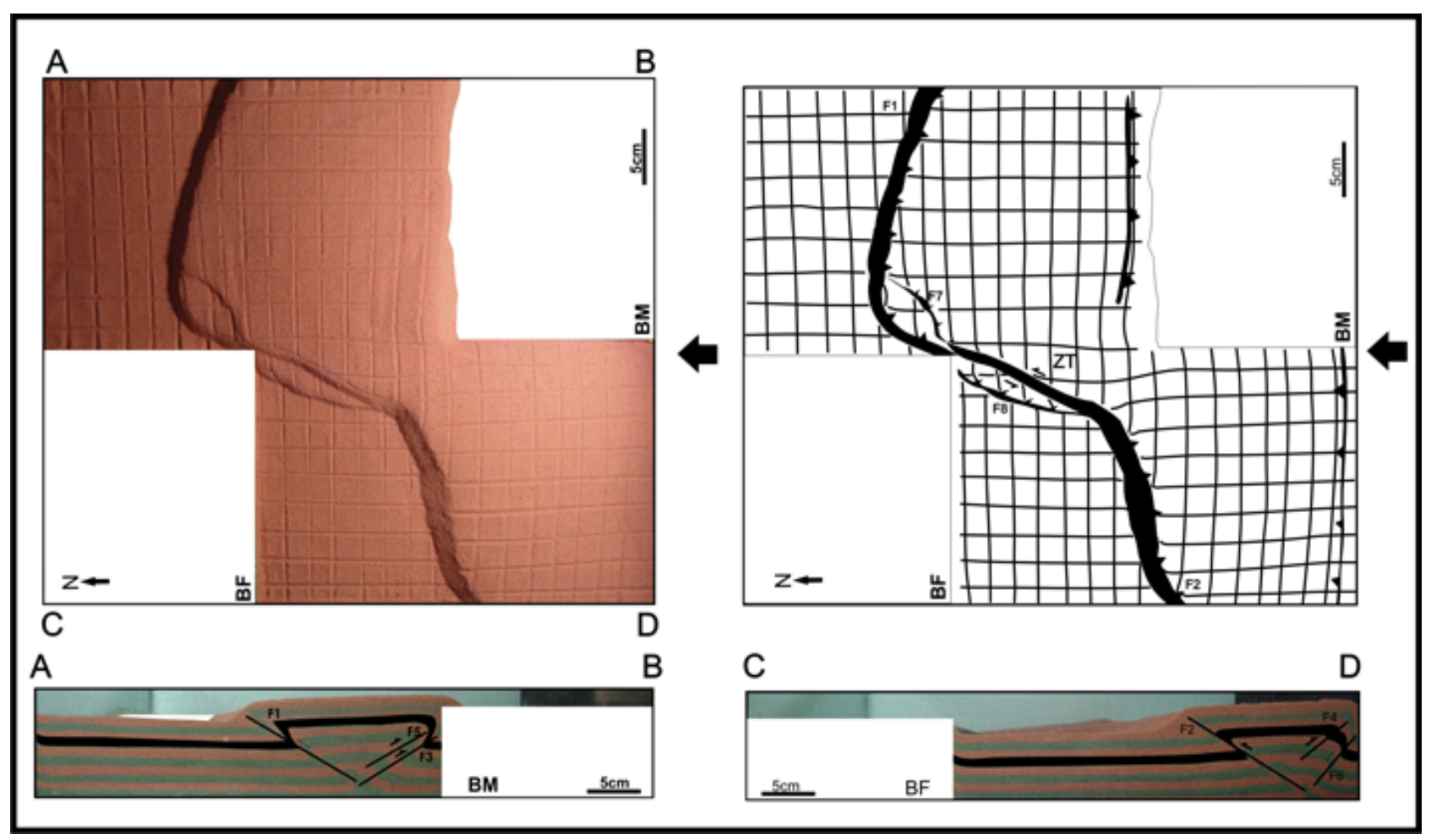

Figura 9 - Visão em mapa (fotografia e interpretação) e perfis do estágio $T_{3}(16 \%$ de encurtamento) mostrando que a orientação da "esquina" do obstáculo de ante-país influencia no desenvolvimento de novas estruturas nas porções leste e oeste da ZT. Na região de pós-país nota-se a dilatação do material (linhas marcadoras) no sentido perpendicular a compressão.

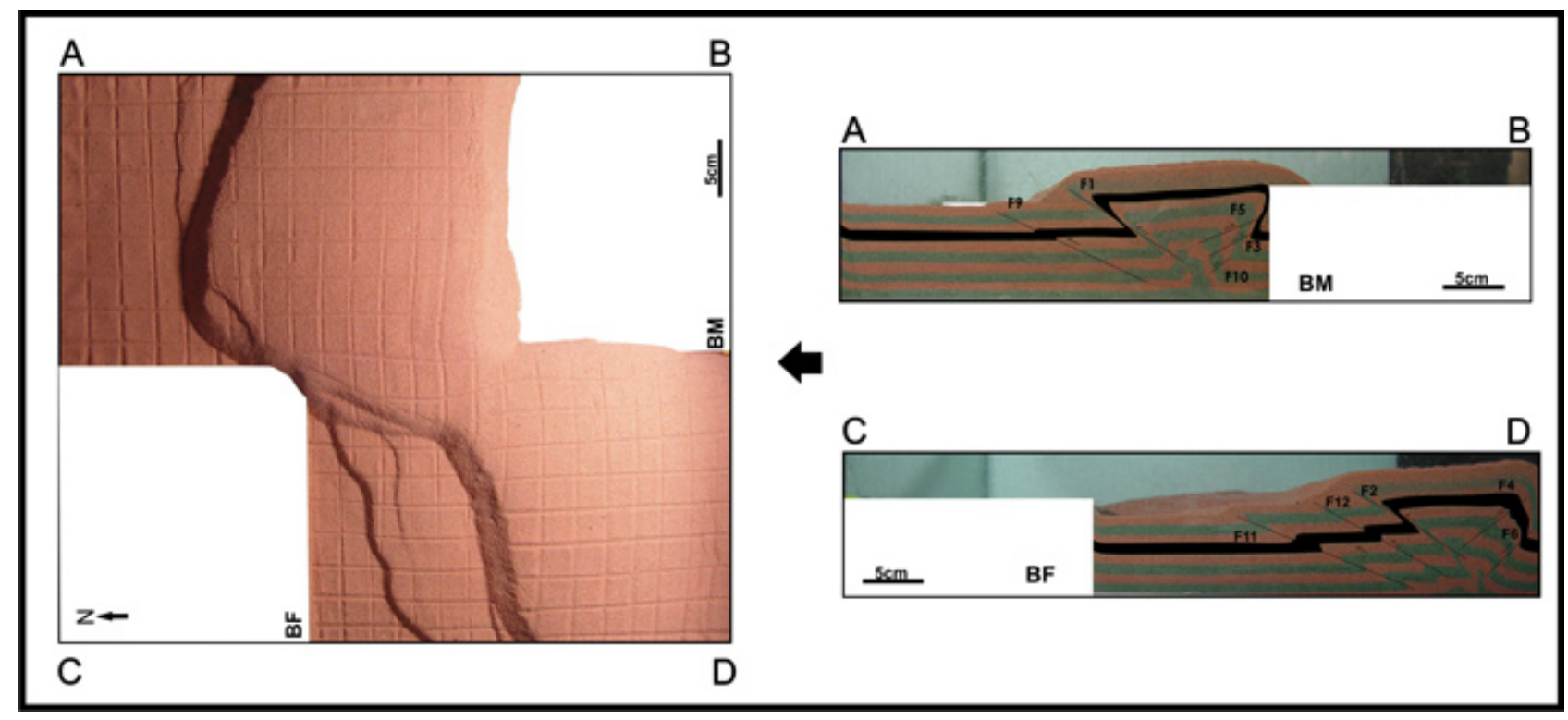

Figura 10 - Fotos em planta e em perfil do estágio $T_{4}(21 \%$ de encurtamento) mostrando o desenvolvimento de novos empurrões. Em frente ao bloco de ante-país, os novos empurrões exibem traços curvos e paralelos aos mais antigos ao contrário do que ocorre a leste do bloco. 
uma melhor definição do pop-up nesta região.

Fato marcante na evolução estrutural deste modelo foi o desenvolvimento de um sistema de falhas transcorrentes conjugadas na porção oeste, a frente do obstáculo da região de pós-país (bloco móvel). As falhas nucleadas com direções NS e NE exibem cinamática sinistral, enquanto àquelas orientadas na direção NW possuem movimentação dextral (Fig. 11). Essas falhas são claramente o reflexo da disposição geométrica dos obstáculos de pós-país e ante-país, pois embora se concentrem junto ao bloco móvel, sua nucleação tem início ao longo de um corredor meridional definido pelos limites E e W dos obstáculos. Como estas zonas são tardias, elas têm tendência a interceptarem as estruturas previamente formadas, como é o caso da transcorrência NS, que corta em alto ângulo os empurrões que definem a saliência principal, na região de ante-país.

A presença de pequenas falhas normais na região de pós-país começa a ficar evidentes em $\mathrm{T}_{4} \mathrm{em}$ bora sua nucleação possa ter iniciado em estágios anteriores. Isso se deve ao fato do material, alçado pelos retro-empurrões, tender a extravasar por cima do bloco endentante, gerando as falhas de colapso. Esse sistema de falhas normais restringe-se a parte mais superior do modelo e é bem delineado quando o encurtamento atinge $30 \%$ (Fig. 12). Para esse valor de encurtamento, que corresponde ao estágio $\mathrm{T}_{5}$, amplifica-se a influência do alto do embasamento, com os cavalgamentos e transcorrências sendo afetados pela esquina do obstáculo. Acentuam-se os traços estruturais NW e aumentou a geometria sigmoidal das linhas de referência NS (a oeste do bloco endentante), devido à movimentação sinistral (Fig. 12).

Análise dos empurrões e retro-empurrões em perfis As estruturas visualizadas nos perfis, empurrões e retro-empurrões, apresentam distinções no que diz respeito ao tempo de nucleação e intensidade da deformação dependendo de sua localização. Embora algum efeito de fricção da areia com o vidro possa ser notado, alguns cortes afastados da parede, feitos para teste, mostraram que esse efeito é desprezível, no que diz respeito ao mergulho e rejeito das falhas. Adicionalmente os valores mostrados são relativos, o que significa que a possível influência desse atrito é válida tanto para os empurrões como para os retroempurrões.

Os perfis da porção leste refletem mais a influência do bloco do pós-país, enquanto as estruturas desenvolvidas na porção oeste são mais susceptíveis a geometria do obstáculo de ante-país. Os empurrões se desenvolvem em maior número na porção oeste do modelo onde o material é encurtado contra o obstáculo do ante-país e sem o bloco endentante. Verifica-se uma discreta diminuição no ângulo de mergulho dos planos de empurrão com o avanço da deformação, mostrando que essas estruturas rotacionaram muito pouco (Fig. 13a). Quanto ao rejeito dessas falhas verificou-se que nos estágios iniciais de deformação eles são discretos, entretanto exibem um forte aumento quando o encurtamento atingi cerca de $15 \%$ (Fig. 13b).

Os retro-empurrões por sua vez, são mais precoces e delineiam melhor e mais rapidamente, um popup na parte leste, onde a vergência é feita para o bloco indentador na região de pós-país. No geral essas falhas exibem uma variação de mergulho ainda mais discreta que a mostrada pelos empurrões e, ao contrário destes, o ângulo de mergulho aumenta com o aumento da compressão (Fig. 14a). No que diz respeito ao rejeito, os retro-empurrões comportam-se exatamente como os empurrões, apresentando um forte incremento a partir de $15 \%$ de encurtamento (Fig. 14b).

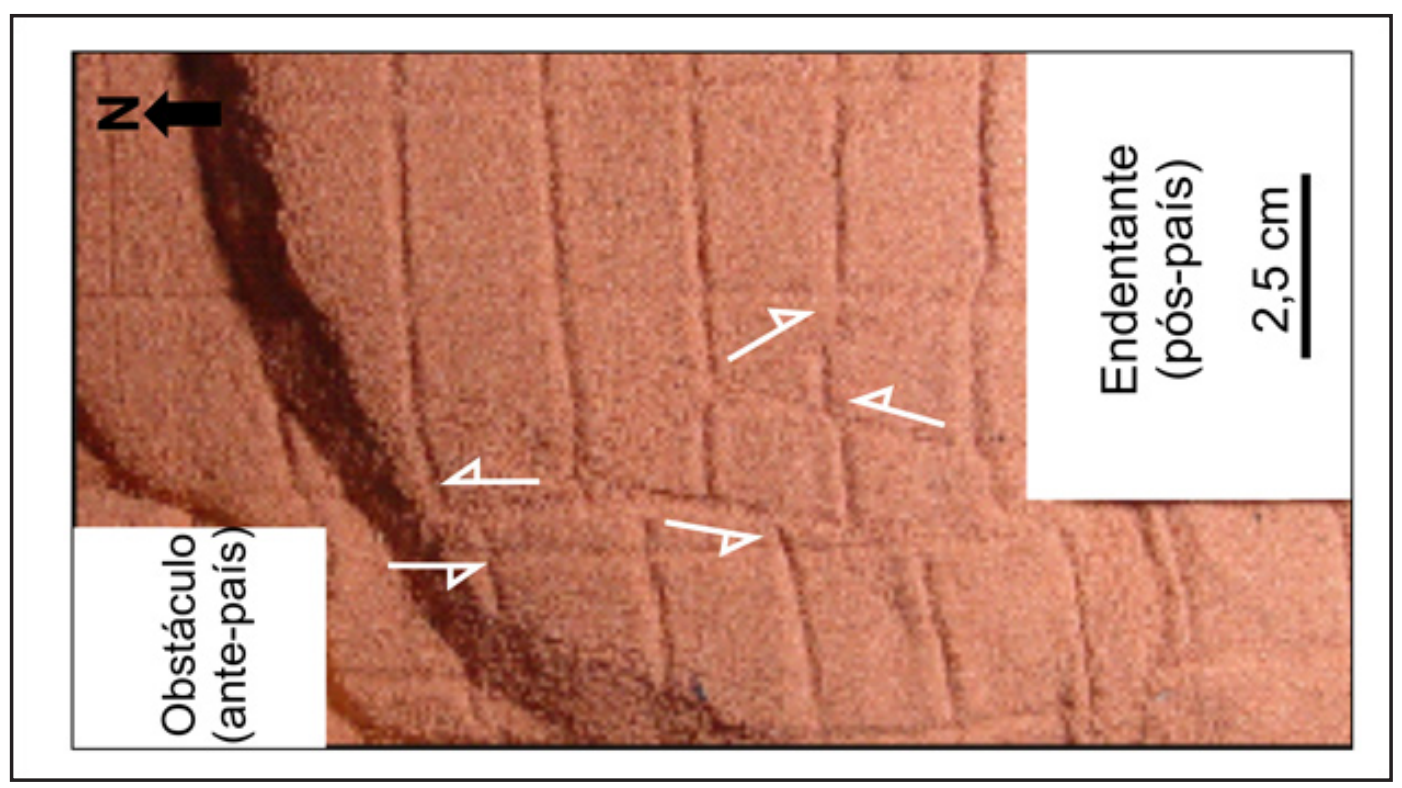

Figura 11 - Foto de parte da superficie do modelo mostrando o desenvolvimento de sistema de falhas transcorrentes conjugadas. 


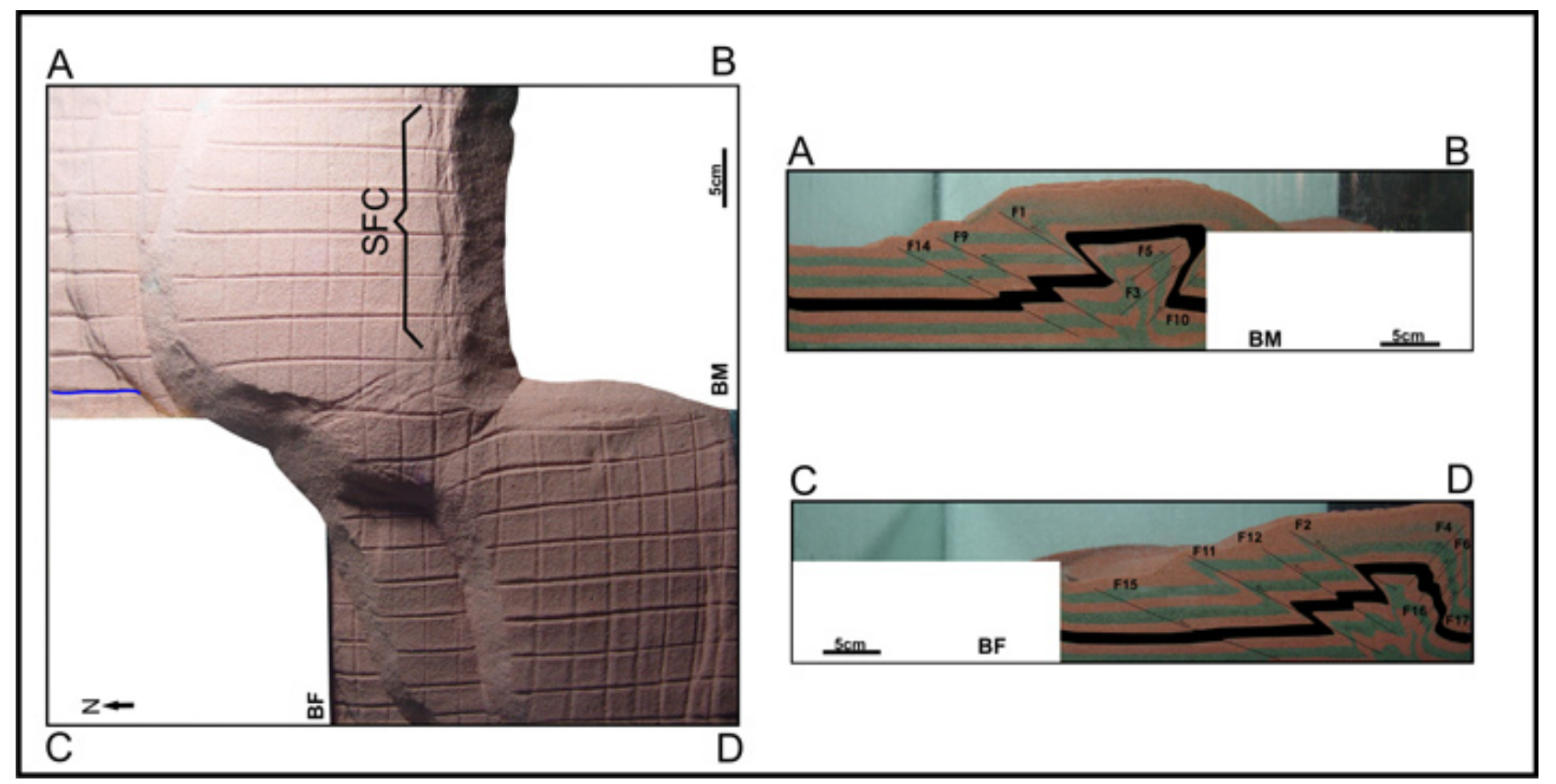

Figura 12 - Sistema de falhas de colapso (SFC) na região de pós-país e o efeito esquina na região ante-país. Estágio $T_{5}(30 \%$ de encurtamento).
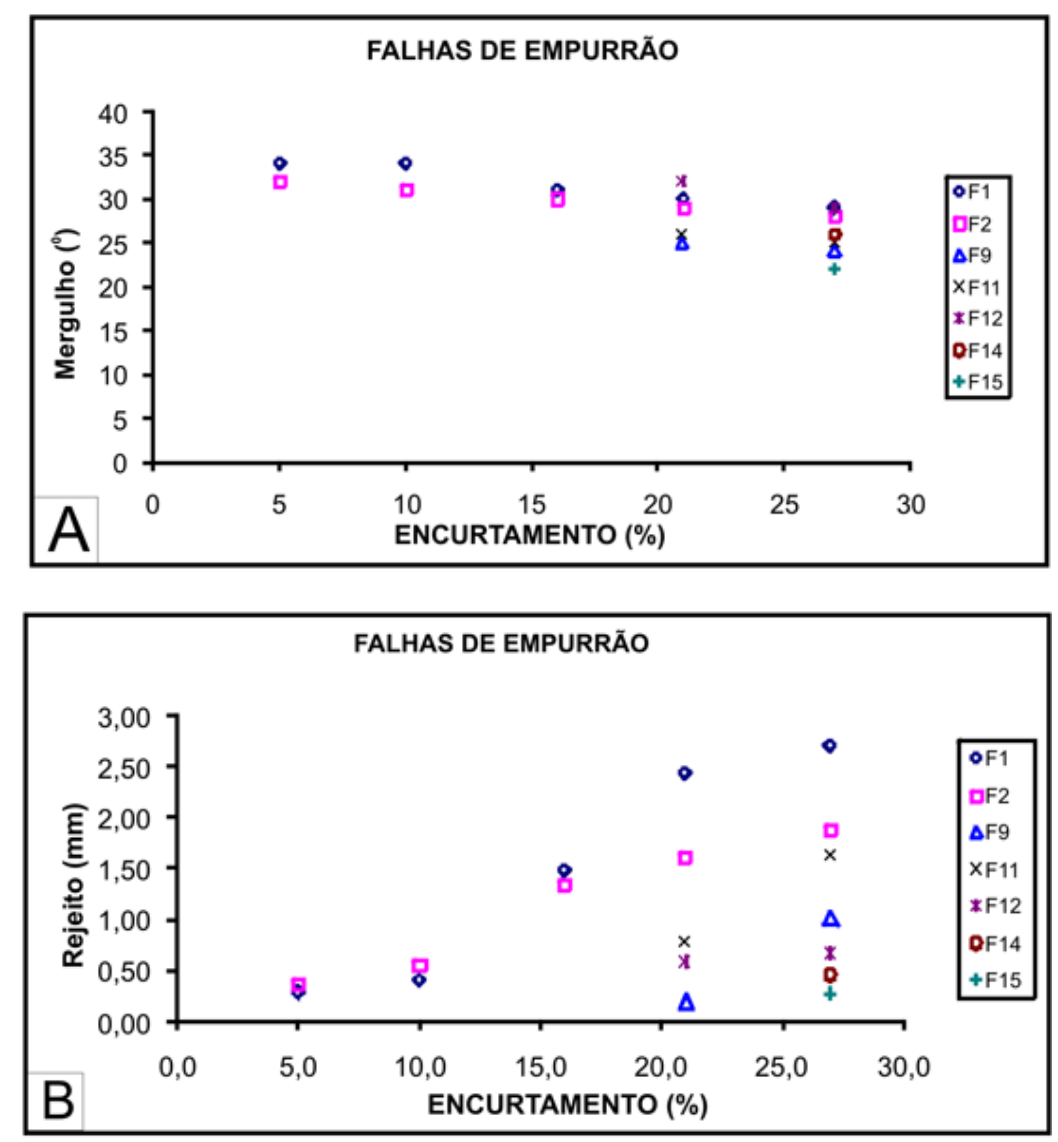

Figura 13 - A) Relação entre o mergulho das falhas de empurrão e a percentagem de encurtamento. Notar que há uma pequena diminuição dos ângulos com o aumento da deformação. B) $O$ rejeito aumenta consideravelmente a partir de $15 \%$ de encurtamento. 
CORRELAÇÕES COM EXEMPLOS REAIS: DISCUSSÕES E CONCLUSÕES A fim de validar interpretações advindas de estudos de laboratório, pesquisadores geralmente buscam análogos de terreno. Isso tem sido feito com respeito à tectônica compressional (Cagnard et. al., 2006, Massoli et al., 2006, entre vários outros), e distensional (McClay et al., 2001, Mart \& Deuteuil, 2000, entre vários outros).

Embora ratifiquemos a premissa original de não buscar, nesse trabalho, reproduzir evolução estrutural de orógenos, mas de possíveis mecanismos de geração de traços curvos, checando a possibilidade de serem fruto de obstáculos em meio a propagação da deformação, mostraremos a seguir exemplos de estruturas reais que foram reproduzidas no âmbito modelagem física analógica realizada.

Primeiramente, o contorno geométrico da saliência desenvolvida nos experimentos realizados permite classificá-la como do tipo assimétrica parabólica. Comparando a geometria produzida em laboratório com exemplos de campo existentes na literatura, verificam-se grandes semelhanças entre a saliência aqui descrita e àquela de Alberta no Canadá, conforme ilustrado na figura 15.

Embora nosso trabalho confirme a importância de obstáculos na geração de traços estruturais curvos, ele mostra também, contrariando algumas propostas da literatura, que tal geometria pode se desenvolver em es- truturas subsidiárias, sem a necessidade de obstáculos, na escala da saliência ou re-entrança formada. Nos experimentos realizados essas estruturas se desenvolveram a frente do obstáculo de ante-país cujo limite é retilíneo, verticalizado e bem maior que o conjunto de saliências formado. Geometricamente, estruturas semelhantes podem ser vistas em mapa da região do Tibet (Fig. 16).

Alguns traços estruturais desenvolvidos em nossos experimentos são geometricamente similares àqueles encontrados em terrenos onde a geometria pré-deformação da bacia sedimentar é enfocada como responsável pela sua formação (Fig. 17). Como o nosso trabalho não envolveu inversão de bacias, estes fatos sugerem que nem a presença de obstáculos nem a geometria pré-deformacional da bacia são condições sine qua non para a formação dessas estruturas, embora que, quando presente, estes fatores possam desempenhar um papel principal.

Diferentemente das estruturas nucleadas na parte frontal do obstáculo de ante-país, o empurrão mais novo gerado na sua lateral exibe certa obliqüidade em relação ao mais antigo. Esse fato pode ser creditado a influência da borda do obstáculo na geração da falha mais jovem. Um análogo real do processo acima descrito parece ter sido desenvolvido no craton Gawler (Austrália), onde o efeito "esquina" pode ter desempenhado papel importante, como visualizado na figura 18.

As transcorrências conjugadas representam ou-
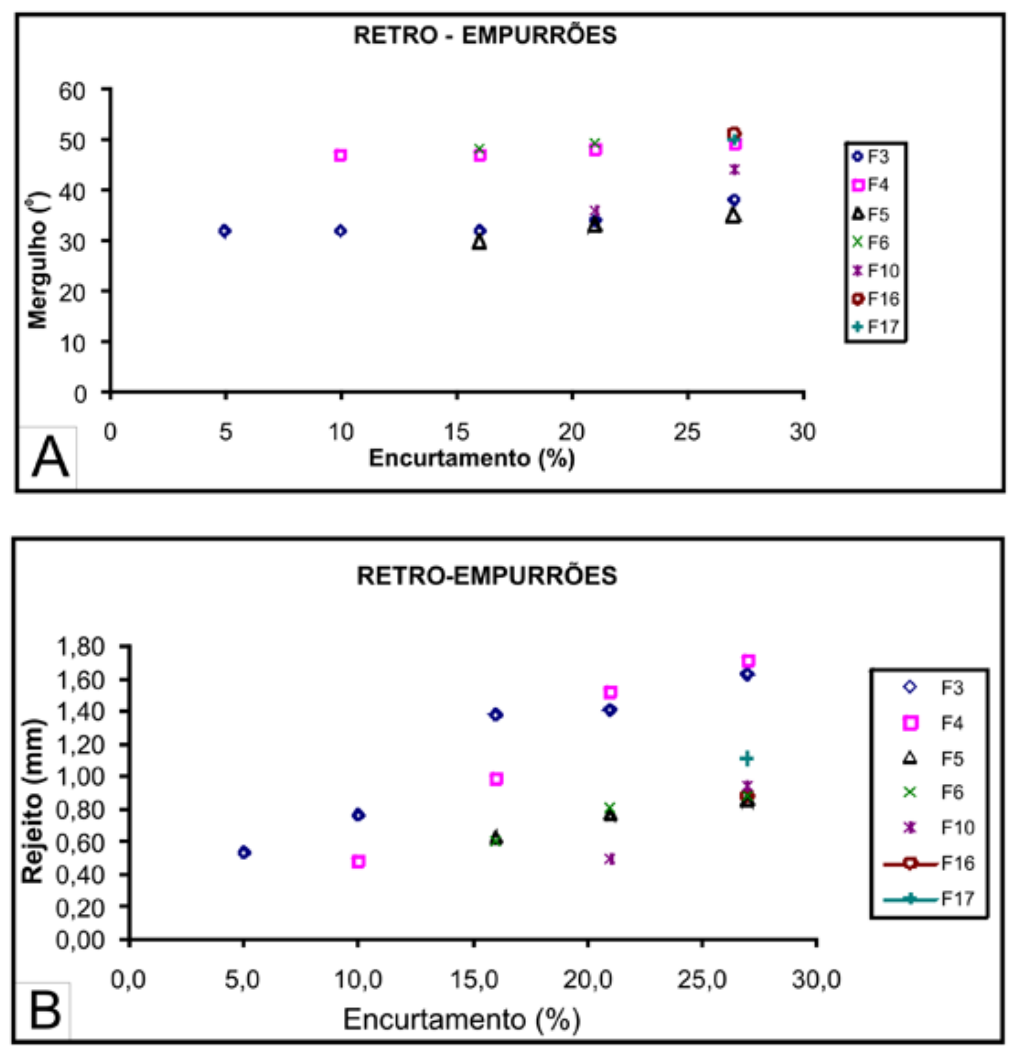

Figura 14 - A) O mergulho dos retro-empurrões aumenta gradativamente com o aumento da compressão. B) Um forte incremento de crescimento é registrado pelos mergulhos das falhas a partir de $15 \%$ de encurtamento. 

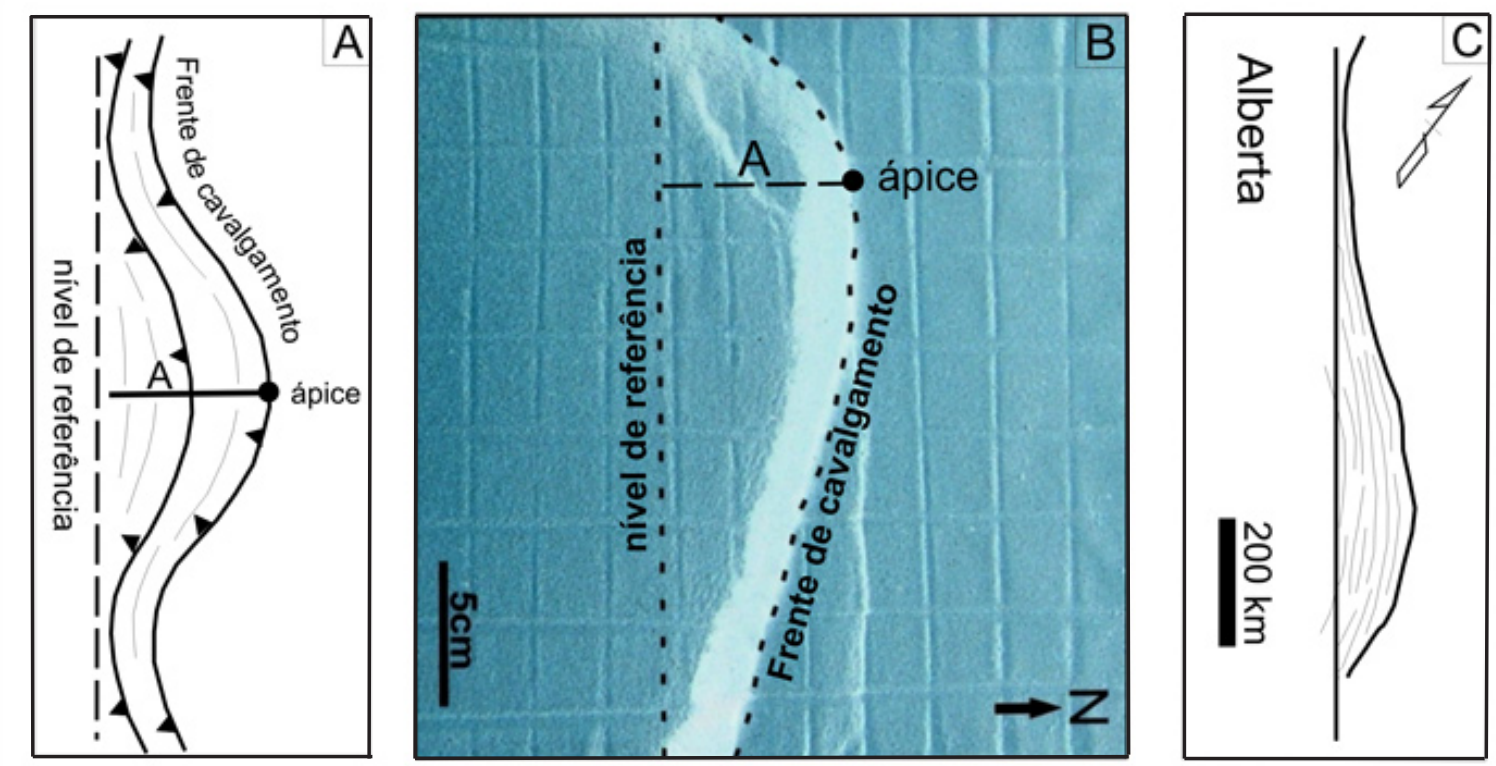

Figura 15 - A) Esquematização de uma saliência simétrica com seus elementos principais. B) Exemplo de saliência formada nos experimentos realizados, exibindo uma geometria assimétrica parabólica. C) Geometria da saliência de Alberta (Canadá), que se assemelha bastante àquela desenvolvida em nossos experimentos. (A e C modificadas de Marshak 2004 e Macedo \& Marshark 1999, respectivamente).

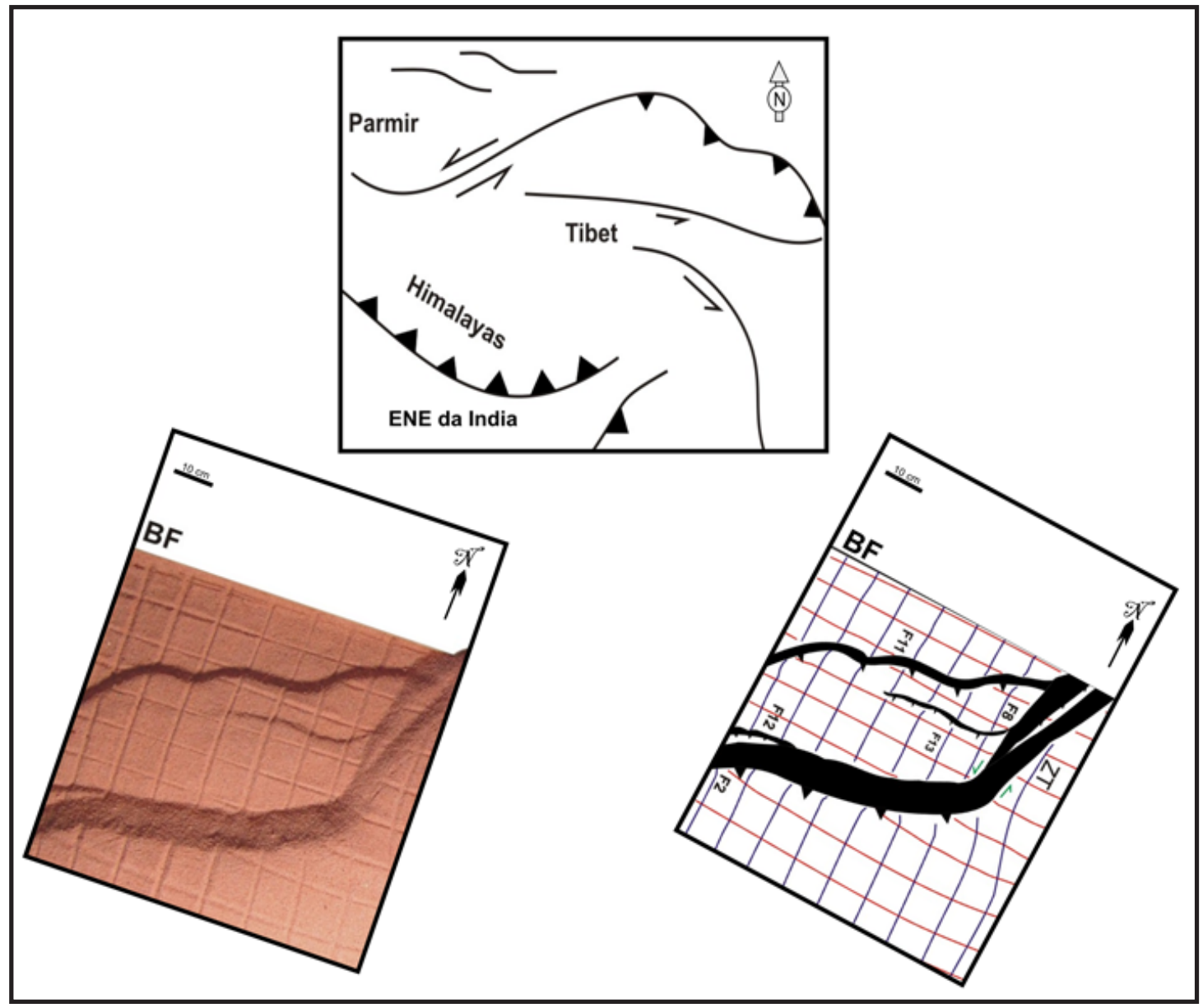

Figura 16 - Formação de saliência em frente ao obstáculo no ante-país. À esquerda, foto em mapa do experimento e a direita sua interpretação. Comparar os traços curvos formados nos experimentos com àqueles do NE da colisão India/Ásia, mostrada em esboço na porção central da figura. 


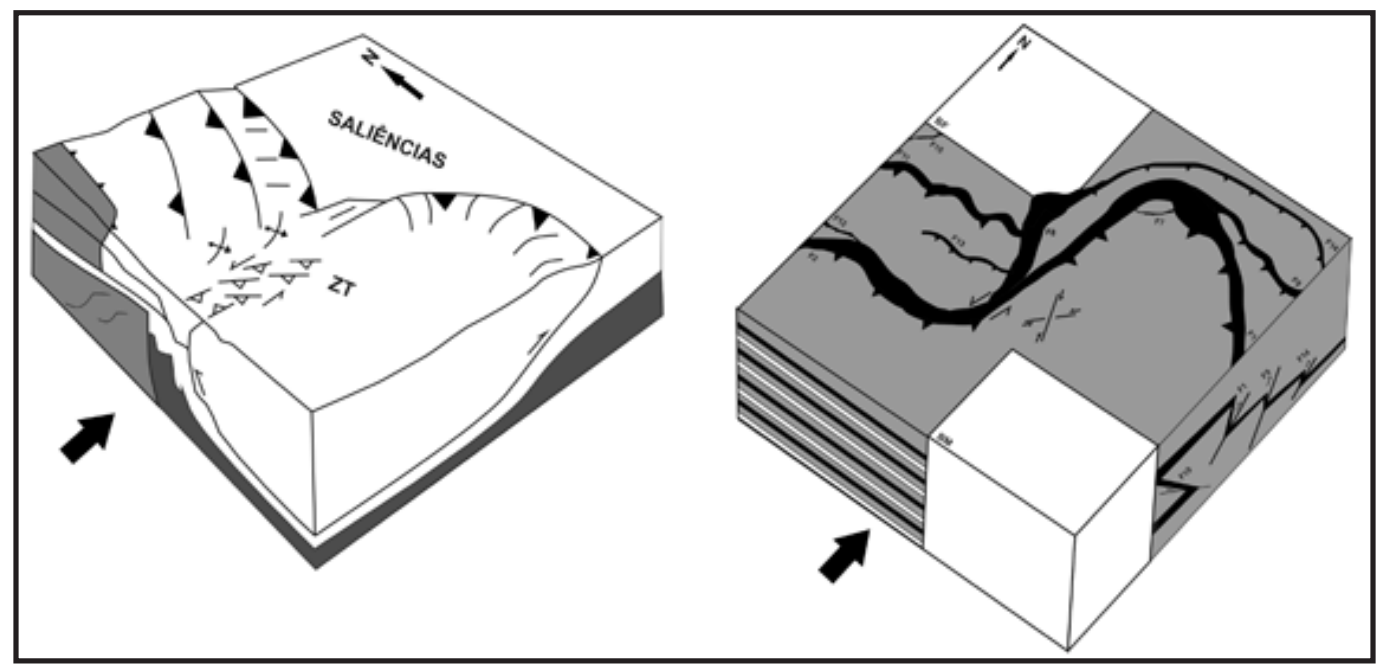

Figura 17 - No oeste dos USA, entre os estados de Nevada e Utah, o desenvolvimento de traços estruturais curvos é atribuido a geometria pré-deformação da bacia (diagrama à esquerda) (Paulsen \& Marshak 1999). Nos experimentos aqui realizados, geometria similar foi adquirida sem a necessidade de irregularidades de bacias prévias (diagrama à direita, que foi rotacionado para facilitar a comparação).

tro tipo de estrutura que aparece nos experimentos e têm correspondentes em orógenos reais. $\mathrm{O}$ desenvolvimento dessas falhas, que foram nucleadas à frente do bloco do pós-país no modelo, é registrado em mapas da região sul dos Apennines. Aqui essas estruturas estão reportadas em regiões onde a presença de hidrocarbonetos se desta- ca como fator econômico importante (Fig. 19).

Com base nos experimentos desenvolvidos, concluímos que a modelagem física em aparato tipo caixa de areia pode ser uma ferramenta poderosa na reprodução e auxílio ao entendimento de muitos dos aspectos geométricos e cinemáticos de cinturões oro-

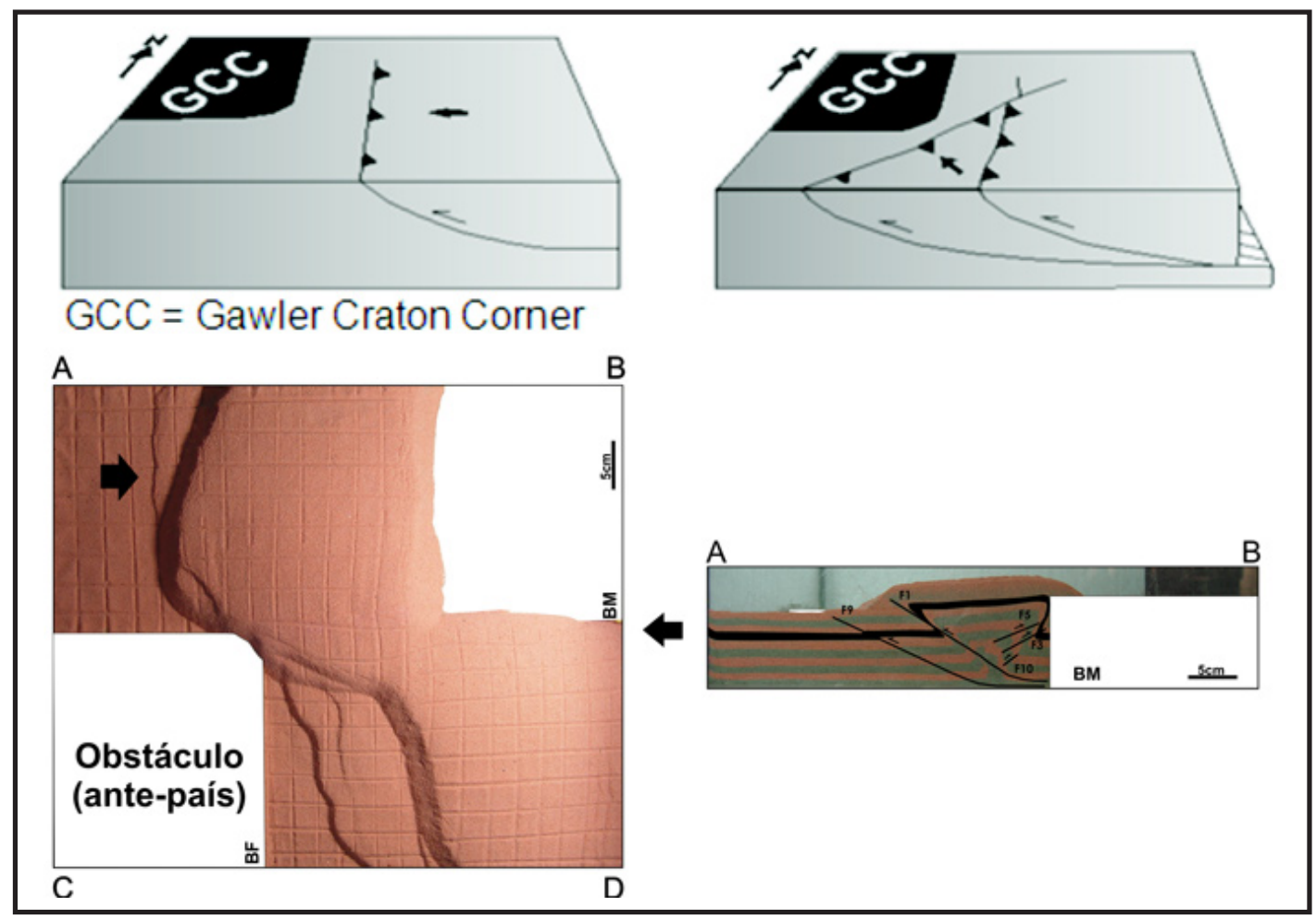

Figura 18 - A "esquina" do obstáculo causando influência na orientação dos empurrões. Note o ângulo (em mapa) formado entre o primeiro e o segundo empurrão, na lateral do obstáculo de ante-país (GCC), no craton Gawler (Modificado de Marshak \& Flotemann, 1996). Efeito similar aparece no modelo experimental (marcado pela seta). 


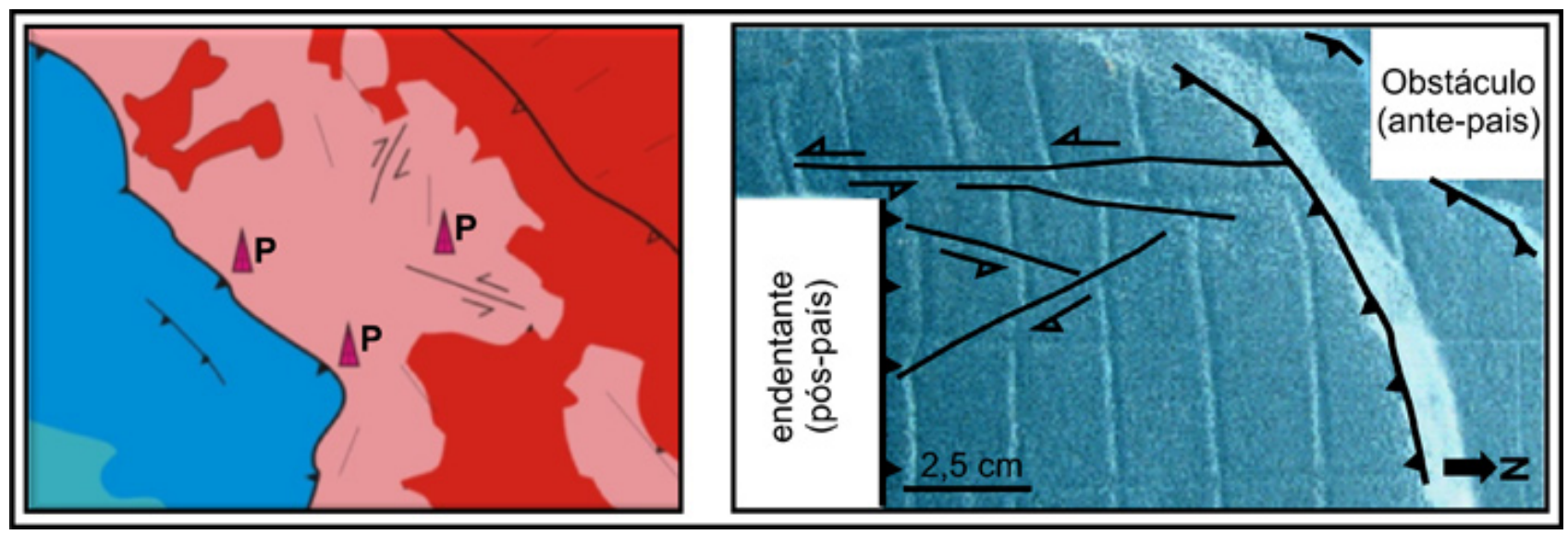

Figura 19 - Sistema de falhas transcorrentes conjugadas, desenvolvidas no sul dos Apennines (Modificado de Turrini \& Rennison 2004) que guarda semelhanças com as falhas desenvolvidas nos experimentos analógicos realizados (foto à direita). Como particularidade no exemplo real, esta zona mostra-se favorável a presença de hidrocarbonetos $(P=$ poços de petróleo $)$.

genéticos, como já demonstrado por diversos outros trabalhos. No experimento realizado verificou-se que o desenvolvimento de traços estruturais curvos comumente mapeados em orógenos compressionais é grandemente influenciado pela geometria e posicionamento de obstáculos de comportamento reológico distinto, tais como alto de embasamento, endentante, etc. Entretanto, essa pode não ser uma premissa universal, uma vez que traços curvos secundários foram nucleados sem a presença de obstáculos com geometria irregular. Para melhor entender essa du- alidade estudos complementares se fazem necessários. Finalmente, a arquitetura final mostrada pelo modelo experimental revela um orógeno assimétrico influenciado pela presença de obstáculos nas regiões de ante-país e pós-país.

Agradecimentos Os autores agradecem ao CNPq, ANP pelas bolsas de Produtividade de Pesquisa, Iniciação Científica. Os agradecimentos são extensivos a um consultor anônimo, cujas criteriosas sugestões em muito contribuiu para a melhoria desse artigo.

\section{Referências}

Barbosa J.S.F. \& Sabate P. 2000. Geological featurs and paleoproterozoic collision of four archean crustal segments of the São Francisco Craton, Bahia, Brazil. Anais da Academia Brasileira de Ciências, 74(2):343-359.

Cagnard F., Brun J.P. \& Gapais D. 2006. Modes of thickening of analogue weak lithospheres. Tectonophysics, 412:145-160

Del Ventisette C., Montanari D., Sani F. Bonini M. 2006. Basin inversion and fault reactivation in laboratory experiments. Journal of Structural Geology, 28:2067-2083.

Eisenstadt G. \& Sims D. 2005. Evaluating sand and clay models: Do rheological differences matter? Journal of Structural Geology, 27:1399-1412.

Flottmann T. Hand M., Close D., Edgoose C., Scrimgeour I. 2004. Thrust tectonic style of the intracratonic Alice Spring and Petermann orogenies, Central Australia. In: MacClay K.R (ed.) Thrust tectonics and hydrocarbon systems. AAPG Memoir, 82:538-557.

Konstantinovskaya E.A., Harris L.B., Poulin J., Ivanov G.M. 2007. Transfer zones and fault reactivation in inverted rift basins: Insights from physical modeling. Tectonophysics, 441:1-26.

Koyi H.A., Sans M., Teixell A., Cotton J., Zeyen H. 2004. The significance of penetrative strain in the restoration of shortened layers - Insights from sand models and the Spanish Pyrenees. In: McClay K.R (ed.) Thrust, tectonics and hydrocarbon systems. AAPG Memoir, 82:207222.

Macedo J.M. \& Marshak S. 1999. Controls on the geometry of fold-thrust belt salients. Geological Society of America Bulettin, 111:1808-1822.

Marshak S. 1988. Kinematics of orocline and arc formation in thin-skinned orogens. Tectonics, 7:73-86.

Marshak S. \& Flottmann T. 1996. Structure and origin of the Feurieu and Nackara arcs in the Adelaide fold-thrust belt, South Australia; salient and recess development in the Delamerian orogen. Journal of Structural Geology, 8:891-908.

Marshak S. \& Wilkerson M.S. 1992. Effect of overburden thickness on thrust-belt geometry and development. Tectonics, 11:560-566.

Marshak S. 2004. Salients, recesses, arcs, oroclines and syntaxes - A review of ideias concerning the formation of map-view curves in fold-thrust belts. In: MacClay K.R. (ed.) Thrust tectonics and hydrocarbon systems. AAPG Memoir, 82:131-156.

Massoli D., Koyi H.A., Barchi M. 2006. Structural evolution of a fold and thrust belt generated by multiple décolle- 
ments: analogue models and natural examples from the Northern Apennines (Italy). Journal of Structural Geology, 28:185-1999.

Mart Y. \& Deuteuil O. 2000. Analogue experiments of propagation of oblique rifts. Tectonophysics, 316:121-132.

McClay K.R., Dooley T., Gloaguen R., Whitehouse P. \& Khalil S. 2001. Analogue modeling of extensional fault archictectures: Comparision with natural rift fault systems. In: PESA Eastern Australia basin symposium, Melbourn, Victoria, p.573-584.

Moores E.M. \& Twiss R.J. 1995. Tectonics. W.H. New York, Freeman and Company, 415p.

Paulsen T. \& Marshak S. 1999. Origin of the Uinta recess, Servier fold-thrust belt, Utah: Influence of basin archicteture on fold-thrust belt geometry. Tectonophysics, 312:203-216.

Ravaglia A., Seno S., Toscani G., Fantoni R. 2006. Mesozoic extension controlling the Southern Alpes thust front geometry under Po Plain, Italy: Insight from sandbox models. Journal of Structural Geology, 28:2084-2096.
Spranggins S.A. \& Dunne W.M. 2002. Deformation history of the Roanoke recess. Appalachians, USA. Journal of Structural Geology, 24:411-433.

Taponier, P., Peltzer G., Le Dain A.Y., Armijo R., Cobbold P. 1982. Propagating extrusion tectonics in Asia: new insights from simple experiments with plasticine. Geology, 10:661-616

Turrini C. \& Rennison P. 2004. Structural style from the Southern Apennines'hydrocarbon Province - An integrated view. In: MacClay K.R. (ed.) Thrust tectonics and hydrocarbon systems. AAPG Memoir, 82: 558-578.

Yamada Y. \& MacClay K. 2004. 3-D analog modeling of inversion thrust structures. In: MacClay K.R. (ed.) Thrust tectonics and hydrocarbon systems. AAPG Memoir, 82:276-301.

Manuscrito ID 11361

Submetido em 23 de maio de 2008 Aceito em 10 de março de 2009 